\title{
Effect of mild dehydration on cognitive function, mood and exercise performance
}

\author{
J.J. Sittlington, P.J. Magee and E.E.A. Simpson \\ Northern Ireland Centre for Food and Health (NICHE), Ulster University, Cromore Road, Coleraine, BT52 1SA
}

The effect of hydration level on cognitive function (CF) and/or mood has proven inconsistent. Some studies have shown mild dehydration (1-2\% loss body mass) to negatively impact on CF together with causing an adverse effect on mood e.g. anxiety ${ }^{(1)}$. Conversely other findings have found moderate dehydration (2-5\% loss body mass) to have no effect on either CF or mood ${ }^{(2)}$ or have had a negative effect on mood alone with no effect on $\mathrm{CF}^{(3)}$. Following exercise, a positive effect on $\mathrm{CF}$ (e.g. faster reaction times) has been found regardless of dehydration level suggesting a potential moderating effect of exercise on $\mathrm{CF}^{(4)}$. The primary aim of this study was to determine the effect of hydration on CF. Secondary objectives included the effect of hydration on both mood and exercise performance and the effect of exercise on mood.

In a cross-over, repeated measures design pilot study, physically-active participants $(\mathrm{n}=12)$ attended a total of four appointments: one baseline (hydrated) and three randomised appointments (one hydrated; two mildly dehydrated ( $1 \cdot 1 \%$ loss body mass)), held at least one week apart. Measures of anthropometry (weight, body mass index, total body water) were taken 24 hours before and at the start of each appointment to establish weight/loss (an indicator of hydration level) and a urine sample was collected to measure urine specific gravity (to confirm hydration level). A sub-maximal Ramp test using a Wattbike Pro was undertaken once per hydration condition to estimate $\mathrm{VO}_{2 \max }$. Cognitive function, specifically attention, was measured at each appointment using CANTAB computerised test battery. During the exercise appointments, $\mathrm{CF}$ was measured following the sub-maximal test during the cool down phase. Participants completed the measures of mood (using PANAS scales) prior to the cognitive function tests at all four appointments (and also following the two exercise tests).

A 2-way ANOVA found no effect of hydration on cognitive function (i.e. movement times; reaction times; information processing speed, all $\mathrm{P}>0 \cdot 05, \mathrm{n}=12)$. There was a significant effect of exercise enhancing the speed of both movement times $(\mathrm{P}<0 \cdot 001)$ and information processing speed (IPS; $\mathrm{P}<0.05)$, but impairing reaction times $(\mathrm{P}<0.05)$. There was also an effect within the interactions of hydration and exercise for IPS $(\mathrm{P}<0.05)$ suggesting that exercising in a hydrated state increases IPS.

\begin{tabular}{|c|c|c|c|c|c|c|c|c|}
\hline & \multicolumn{2}{|c|}{$\begin{array}{l}\text { Hydrated } \\
(\mathrm{n}=12)\end{array}$} & \multicolumn{2}{|c|}{$\begin{array}{l}\text { Dehydrated } \\
\quad(n=12)\end{array}$} & \multicolumn{2}{|c|}{$\begin{array}{l}\text { Before exercise } \\
\quad(\mathrm{n}=11)\end{array}$} & \multicolumn{2}{|c|}{$\begin{array}{l}\text { After exercise } \\
\quad(\mathrm{n}=11)\end{array}$} \\
\hline & Mean & SD & Mean & SD & Mean & SD & Mean & SD \\
\hline Mean PA & $2 \cdot 54$ & .67 & $2 \cdot 19$ & $.81 *$ & $2 \cdot 51$ & .84 & $2 \cdot 24$ & $.79 *$ \\
\hline Mean NA & $1 \cdot 21$ & .36 & $1 \cdot 34$ & $.34^{*}$ & $1 \cdot 34$ & .48 & $1 \cdot 2$ & .22 \\
\hline
\end{tabular}

In relation to mood, there was a decrease in mean Positive Affect (PA; P0.030) together with an increase in mean Negative Affect (NA; P0.047) in the dehydrated group when compared with the hydrated group and the exercise bout also caused a decrease in mean PA (P0.024) (see table). Dehydration $(n=11$; one participant's data was removed from analysis) had a negative effect on Maximum Minute Power, $\mathrm{VO}_{2 \max } \mathrm{ml} / \mathrm{kg} / \mathrm{min}$ and in the Metabolic equivalent of $\mathrm{VO}_{2 \max }($ all $\mathrm{P}<0 \cdot 05)$. In conclusion, these findings suggest that mild dehydration does not negatively impact cognitive function, but may effect mood and exercise performance.

1. Ganio MS, Armstrong LE, Casa DJ et al. (2011) Br. J. Nutr 106, 1535-1543.

2. Adam GE, Carter R III, Cheuvront SN et al. (2008) Physiol. Behav. 93, 748-756.

3. Ely BR, Sollanek KJ, Cheuvront SN et al. (2013) Eur J Appl Physiol 113, 1027-1034

4. Jiminez-Pavon D, Romeo J, Cervantes-Borunda M et al. (2011) J Exerc Sci Fit 9, 58-64. 